\title{
Perancangan dan Implementasi Sistem Pengaturan Kecepatan Motor Arus Searah Tanpa Sikat Menggunakan Metode PID-Robust
}

\author{
Ahmad Fachrudin Istiananda, Ir. Rusdhianto Effendie A.K. M.T., dan Andri Ashfahani S.T., M.T., M.Sc. \\ Jurusan Teknik Elektro Fakultas Teknologi Industri, Institut Teknologi Sepuluh Nopember \\ Jl. Arief Rahman Hakim, Surabaya 60111 \\ e-mail : ahmd.fachrudin@gmail.com,rusdhi@elect-eng.its.ac.id, dan andriashfahani@gmail.com.
}

\begin{abstract}
Abstrak- BLDCM merupakan suatu jenis motor sinkron yang artinya medan magnet yang dihasilkan oleh stator dan medan magnet yang dihasilkan rotor berputar di frekuensi yang sama. Dalam BLDCM, salah satu hal yang sangat penting untuk dikontrol adalah kecepata. Permasalahan yang diteliti dan dianalisis pada Tugas Akhir Perancangan dan Implementasi Sistem Pengaturan Kecepatan Motor Arus Searah Tanpa Sikat Menggunakan Metode PID-Robust adalah respon kecepatan BLDCM terhadap pembebanan yang berubah-ubah. Pengaturan kecepatan BLDCM dirancang menggunakan Kontroler Proposional, Integral dan Derivatif (PID). Kontroler PID-Robust digunakan untuk membantu BLDC pada kondisi pembebanan untuk mempertahankan setpoint. Nilai parameter Kp, Ki, dan Kd sebesar 529,9, 0,00000373 , dan 0,0624 didapat dari perhitungan robust performansi $H_{\infty}$ dengan metode LMI (Linear Matrix Inequality). Setelah dilakukan simulasi, didapatkan bahwa respon plant dengan kontroler PID-Robust dapat mengikuti model referensi yang diinginkan dengan nilai rise time 7,7 untuk beban minimal, 3,75 untuk beban nominal, dan 5,9 untuk beban maksimal serta kuat/robust terhadap gangguan/disturbance.
\end{abstract}

Kata kunci : BLDC Motor, PID, Robust, Performansi $H_{\infty}$

\section{PENDAHULUAN}

$\mathrm{P}$ ada zaman sekarang, teknologi semakin canggih, mulai dari peralatan mekanik, elektrik maupun perangkat lunaknya bersinergi untuk menghasilkan suatu produk ataupun peralatan baru. Motor listrik sebagai penggerak sangat berperan penting dalam dunia industri. Jenis penggerak yang sering dipakai di dunia industri adalah motor brushless DC. Motor ini memiliki beberapa kelebihan dibandingkan motor jenis yang lain seperti tingkat efektifitas serta kesederhanaan dari konstruksi motor. Dalam BLDC motor, kontroler memiliki perang penting dalam mempengaruhi performansi dalam aplikasinya di dunia industri. Hal ini menyebabkan timbulnya ketertarikan manusia dalam kontroler cerdas dan adaptif [1]. Proportional-integral-derivative (PID) banyak digunakan dalam aplikasi kontrol karena sifatnya yang simple dan efektif.

Perubahan parameter dari motor menyebabkan perubahan respon yang cukup signifikan. Metode yang umum dilakukan adalah dengan melakukan penalaan parameter kontroler secara kontinyu. Hal ini tentu saja akan sangat merepotkan karena harus melakukan penalaan parameter kontroler setiap terjadi perubahan beban. Untuk itu diperlukan suatu kontroler yang memiliki sifat kokoh terhadap gangguan maupun perubahan parameter[1].

Meskipun penggunaan kontrol PID mempunyai sejarah yang lama, tiga parameter gain, proporsional gain (Kp), integral gain $(\mathrm{Ki})$, dan derivatif gain $(\mathrm{Kd})$, biasanya bernilai tetap. Kelemahan kontroler PID adalah kapabilitasnya rendah dalam menghadapi ketidakpastian sistem, variasi parameter, dan gangguan dari luar. Sehingga robustness mendapatkan perhatian lebih[2].

Tujuan utama dari perancangan sistem kontrol adalah mampu menstabilkan sistem dengan performansi tertentu. Dalam sistem nyata, ketidakpastian parameter maupun gangguan dari luar dapat mengganggu kestabilan sistem, sehingga kontroler yang dirancang harus robust terhadap ketidakpastian serta gangguan tersebut. Sistem dikatakan memiliki performansi robust apabila sistem mampu menjaga kestabilannya meskipun terdapat ketidakpastian parameter serta gangguan dari luar[2]. Dalam Tugas Akhir ini kontroler dirancang agar memiliki performansi $H_{\infty}$.

Salah satu metode kontrol robust yang sering digunakan adalah kontrol robust $H_{\infty}$. Pada $H_{\infty}$, kontroler didesain untuk meminimalkan pengaruh terburuk keluaran performansi ketika terdapat gangguan yang diberikan pada sistem. Pengaruh terburuk gangguan terhadap keluaran performansi dapat diketahui dengan menghitung $\infty-$ norm dari fungsi alih sistem. $\infty-$ norm dari suatu fungsi alih didefinisikan sebagai

$$
\|G(s)\|_{\infty}=\sup _{\omega}|G(j \omega)|
$$

Dari Persamaan (1), $\infty-$ norm dari suatu fungsi alih adalah nilai maksimal dari plot magnitude Bode. Jika $G(s)$ menyatakan fungsi alih keluaran performansi terhadap gangguan, dan $\infty-$ norm dari $G(s)$ bernilai kecil, maka dapat dikatakan bahwa gangguan yang diberikan teredam sesuai besarnya $\infty-$ norm [2]. 


\section{PERANCANGAN SISTEM}

Proses perancangan sistem pada penelitian ini sesuai dengan diagram blok Gambar 1. Set point masuk pada Kontroler PID-Robust. Komuikasi dari plant motor BLDC dengan kontroler menggunakan Arduino Uno. Aktuator berupa motor BLDC. Plant yang dibuat merupakan plant motor BLDC yang terdiri dari beberapa komponen penyusun yang dirangkai membentuk suatu plant motor BLDC untuk melaksanakan suatu objektif tertentu sesuai dengan tujuan dilaksanakannya Tugas Akhir. Plant motor BLDC sendiri terdiri dari komponen utama yaitu motor arus searah tanpa sikat (BLDC Motor) yang diambil dari AC Inverter merek Daikin, rem elektromagnetik, serta sensor arus. Rem elektromagnetik bekerja untuk memberikan efek pembebanan pada kinerja motor. Pembebanan motor merupakan beban yang akan diterima motor pada saat motor menggerakkan piringan alumunium.

Selain perangkat keras berupa motor BLDC dan rem elektromagnetik, ditambahkan pula beberapa komponen pendukung, seperti driver untuk motor BLDC dan driver untuk rem elektromagnetik. Selain itu, dilengkapi pula sensor arus untuk mengetahui besaran arus yang diberikan pada komponen rem elektromagnetik sebagai efek pembebanan pada motor BLDC. Mikrokontroler Arduino juga akan dipakai pada sistem ini sebagai perantara antara sensor-sensor dan driver dengan komputer. Serta rangkaian pengatur PWM (Pulse Width Modulation) yang digunakan untuk mengatur besarnya sinyal kontrol yang diberikan pada rem untuk membantu besarnya pembebanan rem magnetik.

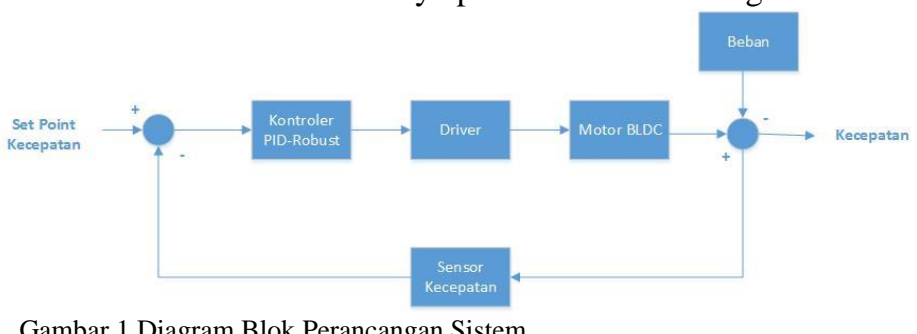

Gambar 1 Diagram Blok Perancangan Sistem

\section{A. Motor Brushless DC [5]}

Motor Brushless DC (BLDC) adalah motor singkron dengan magnet permanen pada rotor dan kumparan jangkar pada stator. Keuntungan paling jelas dari konfigurasi tanpa sikat adalah penghilangan sikat, yang menghilangkan pemeliharaan sikat dan bunga api. Penggunaan kumparan jangkar pada stator membantu konduksi panas pada kumparan. Karena tidak ada kumparan pada rotor, kerugian listrik dalam rotor menjadi minimal. Motor BLDC lebih disukai dibandingkan dengan motor induksi untuk daerah daya sebagian-sebagian. Motor BLDC memiliki efisiensi yang dan faktor daya yang lebih baik dan oleh karena itu, daya keluaran lebih besar untuk kerangka yang sama, karena penguatan medan dipengaruhi oleh magnet permanen dan tidak harus disuplai oleh arus jangkar. Keuntungankeuntungan yang didapat dari motor BLDC disertai dengan peningkatan kompleksitas di kontroler elektronik dan perlunya penginderaan posisi poros. Eksitasi magnet permanen (PM) lebih layak untuk motor kecil, biasanya di bawah $20 \mathrm{~kW}$. Untuk motor yang lebih besar, biaya dan berat magnet menjadi terlalu tinggi, dan itu akan membuat lebih masuk akal untuk memilih eksitasi dengan elektromagnet.

Namun, dengan pengembangan bahan magnet permanen medan tinggi, motor PM dengan kapasitas beberapa megawatt telah dibangun. Meskipun motor BLDC memakan biaya lebih dari motor DC dengan sikat, hal ini akan sepadan seiring dengan banyaknya waktu dan uang yang dihabiskan motor DC dengan sikat jika sikat aus [5]. Rancangan fisik hardware bisa dilihat pada

\section{B. Hall Effect Sensor [4]}

Jika sebuah konduktor berarus diletakkan di dalam medan magnet, akan muncul tegangan yang tegak lurus dengan arus dan medan magnet. Prinsip ini disebut dengan efek Hall.

Jika medan magnet tegak lurus dengan arus seperti ditunjukkan pada gambar 3, akan muncul gaya Lorentz yang bekerja pada elektron-elektron konduktor. Gaya ini akan mengganggu distribusi arus, menyebabkan perbedaan potensial (tegangan). Tegangan ini adalah tegangan Hall $\left(V_{H}\right)$. Hubungan dari besar tegangan Hall dengan arus dan medan magnet ditunjukkan pada persamaan 2 .

$V_{H} \propto I \times B$

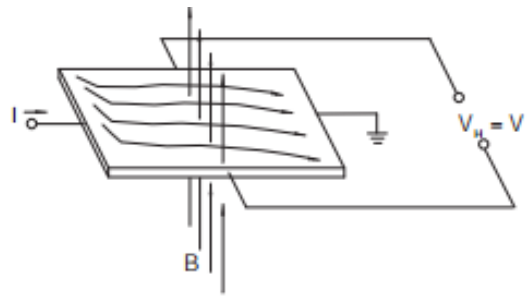

Gambar 2 Prinsip efek hall

Pada motor BLDC, komutasi dilakukan secara elektris. Gambar 3 menggambarkan bagaimana komutasi dapat dilakukan menggunakan 3 buah sensor. Sensor mendeteksi posisi angular poros dan menyampaikan informasi tersebut ke sebuah rangkaian logika. Rangkaian logika tersebut kemudian mengolah informasi posisi rotor untuk mengatur switch dari rangkaian driver motor.

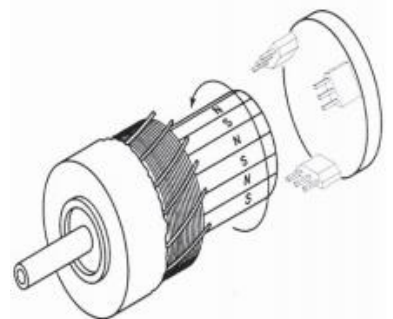

Gambar 3 Peletakkan sensor posisi motor BLDC.

\section{Rem Elektromagnetik [6]}

Rem adalah suatu alat yang digunakan untuk melakukan aksi deselerasi yang akan menurunkan kecepatan dalam 
selang waktu yang ditentukan. Tipe rem yang umum digunakan adalah rem yang menggunakan gaya gesek untuk memberikan gaya lawan terhadap gaya gerak. Namun pada sistem pengereman elektromagnetik menggunakan gaya elektromagnetik untuk memperlambat suatu gerakan, yang umumnya adalah gerakan poros.

Sebuah piringan dengan bahan logam non-feromagnetik terpasang dengan poros yang berputar. Piringan tersebut diapit oleh sisi rotor berupa sistem lilitan elektromagnetik yang dapat membangkitkan medan magnet dari aliran listrik. Arus listrik menimbulkan medan magnet pada lilitan dan logam piringan yang memotong medan magnet tersebut akan menimbulkan arus eddy pada piringan itu sendiri.

Arus eddy ini akan menimbulkan medan magnet yang arahnya berlawanan dengan medan magnet sebelumnya, sehingga menghambat gerakan putar dari poros tersebut. Rem elektromagnetik akan optimal untuk memberikan penurunan kecepatan, bukan untuk menghentikan gerak suatu objek. Sehingga rem ini sering diaplikasikan untuk sistem pengereman pada roller coaster, kereta api dan juga digunakan pada alat dinamometer untuk pengukuran torsi suatu mesin.

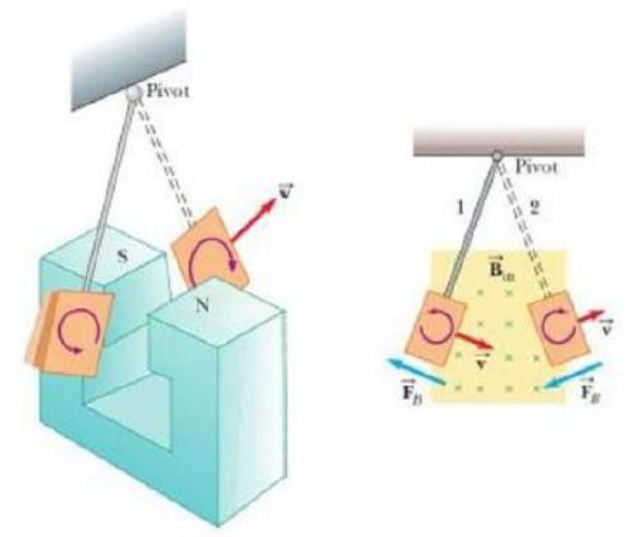

Gambar 4 Prinsip Arus Eddy Pada Logam yang Bergerak

\section{Arduino [7]}

Arduino adalah pengendali mikro single-board yang bersifat open-source, diturunkan dari wiring platform, dirancang untuk memudahkan penggunaan elektronik dalam berbagai bidang. Hardwarenya memiliki prosesor Atmel AVR dan softwarenya memiliki bahasa pemrograman sendiri. Saat ini Arduino sangat populer di seluruh dunia. Banyak pemula yang belajar mengenal robotika dan elektronika lewat Arduino karena mudah dipelajari. Bahasa yang dipakai dalam Arduino bukan assembler yang relatif sulit, tetapi bahasa $\mathrm{C}$ yang disederhanakan dengan bantuan pustaka-pustaka (libraries) Arduino. Arduino juga menyederhanakan proses bekerja dengan mikrokontroler.

Arduino Uno adalah board mikrokontroler berbasis Atmega328. Alat ini mempunyai 14 pin input/output digital dan 6 diantaranya dapat digunakan sebagai output PWM, 6 input analog, resonator keramik $19 \mathrm{MHz}$, koneksi USB, soket listrik, ICSP header, dan tombol reset. Gambar 3 merupakan tampilan fisik dari Arduino Uno. Dengan kabel USB alat ini mudah dihubungkan ke komputer dan dapat diaktifkan dengan baterai atau adaptor AC ke DC. Tabel 1 menjelaskan mengenai spesifikasi Arduino Uno:

Tabel 1.

Spesifikasi Arduino Uno

\begin{tabular}{|c|c|c|}
\hline Mikrokontroler & & Atmega328 \\
\hline Tegangan operasi & & $5 \mathrm{~V}$ \\
\hline $\begin{array}{l}\text { Tegangan } \\
\text { (direkomendasikan) }\end{array}$ & input & $7-12 \mathrm{~V}$ \\
\hline Tegangan input (batasan) & & $6-20 \mathrm{~V}$ \\
\hline Pin inputloutput digital & & $\begin{array}{l}14 \text { (6 diantaranya output } \\
\text { PWM) }\end{array}$ \\
\hline Pin input analog & & 6 \\
\hline Arus DC tiap pin $\mathrm{I} / \mathrm{O}$ & & $40 \mathrm{~mA}$ \\
\hline Arus DC untuk pin $3,3 \mathrm{~V}$ & & $50 \mathrm{~mA}$ \\
\hline
\end{tabular}

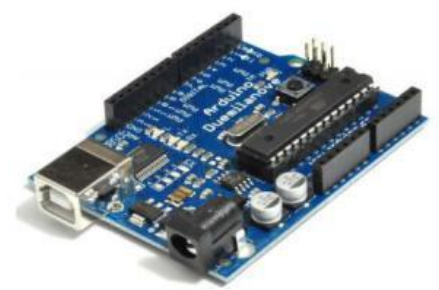

Gambar 5. Tampilan Fisik Arduino Uno

\section{E. Identifikasi Plant}

Fungsi transfer plant didapatkan dengan melakukan identifikasi pada plant. Fungsi transfer digunakan untuk menggantikan plant pada simulasi dengan persamaan matematika. Identifikasi yang dilakukan dengan

memberikan sinyal PRBS (Pseudo Random Binary Sequence) pada input motor dan mengambil output berupa kecepatan motor. Dari data input dan output motor itulah akan didapatkan model matematis plant. Metode yang digunakan untuk mendapatkan model matematis plant ini yaitu dengan menggunakan System Identification Toolbox Matlab. Tahap ini dilakukan sehingga didapatkan fungsi transfer plant untuk beban minimal, nominal, dan maksimal. Fungsi transfer plant dapat dilihat pada Tabel 2.

Tabel 2.

Fungsi Transfer Plant

\begin{tabular}{ccccc}
\hline \hline Beban & $\begin{array}{c}\text { Tegangan } \\
\text { input } \\
\text { beban }\end{array}$ & Fungsi Alih & $\begin{array}{c}\text { Fit to } \\
\text { Estimati } \\
\text { on }\end{array}$ & MSE \\
\hline Minimal & 16 Volt & $\frac{428,8 s+1279}{s^{2}+2,351 s+0,7318}$ & $78,9 \%$ & 376 \\
Nominal & 20 Volt & $\frac{536,2 s+1969}{s^{2}+3,461 s+1,185}$ & $78,12 \%$ & 346 \\
Maksima & 24 Volt & $\frac{460,3 s+1396}{s^{2}+2,47 s+0,8689}$ & $79,55 \%$ & 271 \\
\hline
\end{tabular}

\section{F. Desain Kontroler}

Pada hasil identifikasi, didapatkan fungsi transfer plant pada beban nominal sebagai berikut: 


$$
\frac{122,2386}{s^{2}+28,9879 s+134,5795}
$$

Dari Persamaan (5) yang merupakan model plant dari beban nominal, akan didesain kontroler PID-Robust untuk mengendalikan model tersebut. Setelah fungsi alih dari sistem telah didapatkan, langkah selanjutnya adalah merancang kontroler untuk pengaturan kecepatan motor. Kontroler digunakan untuk membuat plant mengikuti model referensi yang diinginkan sekalipun motor BLDC diberi beban. Pertama-tama, dirumuskan dahulu gain statefeedback yang mampu menjamin kestabilan sistem lup tertutup berdasarkan kriteria Lyapunov. Selain mampu menjamin kestabilan sistem, performansi $H_{\infty}$ juga disertakan dalam perumusan pertidaksamaan Lyapunov yang kemudian akan diubah ke dalam bentuk LMI.

Sebelum merancang kontroler PID-Robust, diperlukan model referensi yang diinginkan. Koefisien numerator dan denumerator fungsi penghantar persamaan (3), akan dimisalkan menjadi variabel tetap agar lebih mudah dalam mendesain kontroler. Sehingga fungsi penghantar plant akan menjadi :

$$
G(s)=\frac{Y(s)}{U(s)}=\frac{K}{s^{2}+A s+B}
$$

dimana :

$$
\begin{aligned}
& K=1969 \\
& A=3,461 \\
& B=1,185
\end{aligned}
$$

Kontroler PID-Robust merupakan kontroler berbasis model. Artinya, diperlukan sebuah pemodelan fungsi alih yang baik agar kontroler yang telah didesain dapat bekerja secara optimal. Fungsi alih yang digunakan merupakan fungsi alih motor BLDC pada pembebanan maksimal. Fungsi alih ini tidak bisa langsung digunakan untuk merancang kontroler PID-Robust, melainkan harus diubah terlebih dahulu ke dalam bentuk state-space. Pada pembebanan maksimal, representasi fungsi alih (\$y)ang bernilai RMSE paling kecil adalah sebagai berikut:

$$
\frac{\Omega(s)}{E a(s)}=\frac{K}{s^{2}+a s+b}
$$

Persamaan beda dari fungsi alih ini menjadi model matematika input $E a$ output $\Omega$

$$
\begin{aligned}
& \ddot{\Omega}+a \dot{\Omega}+b \Omega=K E a \\
& \ddot{\Omega}=-a \dot{\Omega}-b \Omega+K E a
\end{aligned}
$$

Misal state $x_{1}=\dot{\Omega} ; x_{2}=\Omega ;$ dan $x_{3}=\int \Omega$

$$
\begin{aligned}
& \dot{x}_{2}=\dot{\Omega}=x_{1} \\
& \dot{x}_{3}=\Omega=x_{2}
\end{aligned}
$$$$
\dot{x}_{1}=\ddot{\Omega}=-a \dot{\Omega}-b \Omega+k E a
$$

Bentuk state-space yang digunakan pada Tugas Akhir ini adalah bentuk controllable canonical form [17]. Bentuk state-space untuk orde 2 tersebut mempunyai struktur sebagai berikut:

$$
\left[\begin{array}{c}
\dot{x}_{1} \\
\dot{x}_{2} \\
\dot{x}_{3}
\end{array}\right]=\left[\begin{array}{ccc}
-a & -b & 0 \\
1 & 0 & 0 \\
0 & 1 & 0
\end{array}\right]\left[\begin{array}{l}
x_{1} \\
x_{2} \\
x_{3}
\end{array}\right]+\left[\begin{array}{c}
K \\
0 \\
0
\end{array}\right] E a
$$

$$
y=\left[\begin{array}{lll}
0 & 1 & 0
\end{array}\right]\left[\begin{array}{l}
x_{1} \\
x_{2} \\
x_{3}
\end{array}\right]
$$

Berdasarkan bentuk model state-space dari Persamaan 3.1 dapat kita simpulkan bahwa gain dari $K_{1}, K_{2}$ dan $K_{3}$ sebagai berikut:

dimana

$$
K=\left[\begin{array}{lll}
K_{1} & K_{2} & K_{3}
\end{array}\right]
$$

$$
\begin{aligned}
& K_{1}=K_{d} \\
& K_{2}=K_{p} \\
& K_{3}=K_{i}
\end{aligned}
$$

Persamaan (9) dan (10) merupakan gain yang didapat dari parameter oleh persamaan diferensial untuk Robustness dengan performansi $H_{\infty}$ menggunakan penyelesaian dengan metode LMI (Linear Matrix Inequalities), sinyal kontrol PID-Robust yang nantinya akan didesain pada diagram blok program kontroler dengan menggunakan MATLAB.

Model motor dapat di ketahui dengan cara analisa persamaan beda yang digunakan secara keseluruhan, selanjutnya dicari analisa kestabilan Lyapunov, yang di dapat dengan persamaan berikut

Jadi agar sistem terjamin kestabilannya, harus terdapat matriks simetris $P$ yang memenuhi LMI:

1) $P>0$

2) $\left[\begin{array}{cc}A_{i}{ }^{T} P+P A_{i}-K_{j}{ }^{T} B_{u, i}{ }^{T} P-P B_{u, i} K_{j} & P B_{w, i} \\ B_{w, i}{ }^{T} P & 0\end{array}\right]<0$

Jika Pertidaksamaan menunjukkan $L_{2}$-Gain sistem, dan terdapat fungsi Lyapunov $(x(t))=x(t)^{T} P x(t), P>0$, dan $\gamma \geq 0$ sehingga untuk semua $t$,

$\dot{V}\left(x(t)+z_{1}(t)^{T} z_{1}(t)-\gamma^{2} w(t)^{T} w(t)<0 ; \forall t \geq 0\right.$

maka $L_{2}$-Gain sistem memiliki nilai kurang dari $\gamma$ [11].

Dari Pertidaksamaan (3.25) komponen $\dot{V}(x(t))$ memiliki bentuk seperti pada Persamaan (3.23), sedangkan komponen $z_{1}(t)^{T} z_{1}(t)$ dapat dijabarkan dari (3.20) sebagai berikut:

$$
\begin{aligned}
& z_{1}(t)^{T} z_{1}(t)=\left[C_{z 1, i} x(t)\right]^{T}\left[C_{z 1, i} x(t)\right] \\
& z_{1}(t)^{T} z_{1}(t)=x(t)^{T} C_{z 1, i} x(t)^{T} C_{z 1, i} x(t)^{T} \\
& z_{1}(t)^{T} z_{1}(t)=\left[\begin{array}{l}
x(t) \\
w(t)
\end{array}\right]^{T}\left[\begin{array}{cc}
C_{z 1, i}{ }^{T} C_{z 1, i} & 0 \\
0 & 0
\end{array}\right]\left[\begin{array}{l}
x(t) \\
w(t)
\end{array}\right]
\end{aligned}
$$

Selanjutnya, komponen $\gamma^{2} w(t)^{T} w(t)$ dapat dijabarkan sebagai berikut:

$$
\begin{aligned}
& \gamma^{2} w(t)^{T} w(t)=[w(t)]^{T}\left[\gamma^{2} I\right][w(t)] \\
& \gamma^{2} w(t)^{T} w(t)=\left[\begin{array}{c}
x(t) \\
w(t)
\end{array}\right]^{T}\left[\begin{array}{cc}
0 & 0 \\
0 & \gamma^{2} I
\end{array}\right]\left[\begin{array}{c}
x(t) \\
w(t)
\end{array}\right]^{T}
\end{aligned}
$$

Substitusi (3.16), (3.22), dan (3.23) pada Pertidaksamaan (3.20) akan didapat

$$
\dot{V}\left(x(t)+z_{1}(t)^{T} z_{1}(t)-\gamma^{2} w(t)^{T} w(t)<0\right.
$$




$$
\begin{aligned}
& {\left[\begin{array}{l}
x(t) \\
w(t)
\end{array}\right]^{T}\left[\begin{array}{cc}
A_{i}{ }^{T} P+P A_{i}-K_{j}{ }^{T} B_{u, i}{ }^{T} P-P B_{u, i} K_{j} & P B_{w, i} \\
B_{w, i}{ }^{T} P & 0
\end{array}\right]\left[\begin{array}{l}
x(t) \\
w(t)
\end{array}\right]+} \\
& {\left[\begin{array}{l}
x(t) \\
w(t)
\end{array}\right]^{T}\left[\begin{array}{cc}
C_{z 1, i}{ }^{T} C_{z 1, i} & 0 \\
0 & 0
\end{array}\right]\left[\begin{array}{l}
x(t) \\
w(t)
\end{array}\right]-\left[\begin{array}{c}
x(t) \\
w(t)
\end{array}\right]^{T}\left[\begin{array}{cc}
0 & 0 \\
0 & \gamma^{2} I
\end{array}\right]\left[\begin{array}{c}
x(t) \\
w(t)
\end{array}\right]^{T}<}
\end{aligned}
$$

$$
\begin{aligned}
& {\left[\begin{array}{c}
x(t) \\
w(t)
\end{array}\right]^{T}\left\{\left[\begin{array}{cc}
A_{i}{ }^{T} P+P A_{i}-K_{j}{ }^{T} B_{u, i}{ }^{T} P-P B_{u, i} K_{j} & P B_{w, i} \\
B_{w, i}{ }^{T} P & \gamma^{2} I
\end{array}\right]+\right.} \\
& \left.\left[\begin{array}{c}
C_{z 1, i}{ }^{T} \\
0
\end{array}\right]\left[\begin{array}{ll}
C_{z 1, i} & 0
\end{array}\right]\right\}\left[\begin{array}{l}
x(t) \\
w(t)
\end{array}\right]<0
\end{aligned}
$$

Dari Pertidaksamaan, akan didapat LMI:

$$
\begin{aligned}
& {\left[\begin{array}{cc}
A_{i}{ }^{T} P+P A_{i}-K_{j}{ }^{T} B_{u, i}{ }^{T} P-P B_{u, i} K_{j} & P B_{w, i} \\
B_{w, i}{ }^{T} P & \gamma^{2} I
\end{array}\right]+} \\
& {\left[\begin{array}{c}
C_{z 1, i}{ }^{T} \\
0
\end{array}\right]\left[\begin{array}{ll}
I]\left[C_{z 1, i}\right. & 0
\end{array}\right]<0}
\end{aligned}
$$

Penerapan Schur Complement pada LMI (18) dan premultiplying dan post-multiplying LMI (18) dengan matriks $P^{-1}$ akan menghasilkan LMI (19).

$$
\left[\begin{array}{ccc}
A_{i}{ }^{T} Q+Q A_{i}-K_{j}{ }^{T} B_{u, i}{ }^{T} P-P B_{u, i} K_{j} & B_{w, i} & Q C_{z 1, i}{ }^{T} \\
B_{w, i}{ }^{T} & -\gamma^{2} I & 0 \\
C_{z 1, i} Q & 0 & -I
\end{array}\right]
$$

dengan

$$
Q=P^{-1} \text { dan } Y_{j}=K_{j} P^{-1}
$$

Jika terdapat matriks simetris $Q>0$ yang memenuhi LMI (20), maka sistem (3.13) dikatakan stabil dengan tingkat pelemahan gangguan $w(t)$ terhadap keluaran $z_{1}(t)$ kurang dari $\gamma$.

Untuk menyelesaikan LMI (20), dapat digunakan LMI Toolbox dari MATLAB. Nilai parameter $\gamma$ divariasi antara 1 dan 0 dan didapat hasil terbaik yaitu ketika $\gamma=0.5$. Adapun hasil matriks $P, Y$ yang didapat adalah

$$
\begin{aligned}
& P=\left[\begin{array}{ccc}
7,69 * 10^{-9} & 9,57 * 10^{-7} & 6,74 * 10^{-15} \\
9,57 * 10^{-7} & 0,0080 & 5,63 * 10^{-11} \\
6,74 * 10^{-15} & 5,63 * 10^{-11} & 7,45 * 10^{-9}
\end{array}\right] \\
& Y=10^{5} *[-1,5197 \quad 0,6629 \quad 0,000000163]
\end{aligned}
$$

Dari Persamaan dapat dihitung gain state-feedback $K$ untuk parameter gain dari $K_{p}, K_{i}$ dan $K_{d}$ pada PID-Robust, yaitu

$$
K=\left[\begin{array}{lll}
0,0624 & 529,9 & 0,00000373
\end{array}\right]
$$

Setelah diketahui nilai pole-pole dari model maka dapat diketahui nilai $\mathrm{Kp}$, $\mathrm{Ki}$, dan $\mathrm{Kd}$ sebesar 150, 0.0001, dan 0.0236 .

\section{IMPLEMENTASI DAN ANALISIS DATA}

\section{A. Simulasi}

Pemodelan dilakukan dengan metode seperti yang dijelaskan pada bab sebelumnya. Untuk simulasi kontroler digunakan software MATLAB. Gambar 7 menunjukkan diagram blok simulasi kontroler dengan menggunakan metode PID-Robust.

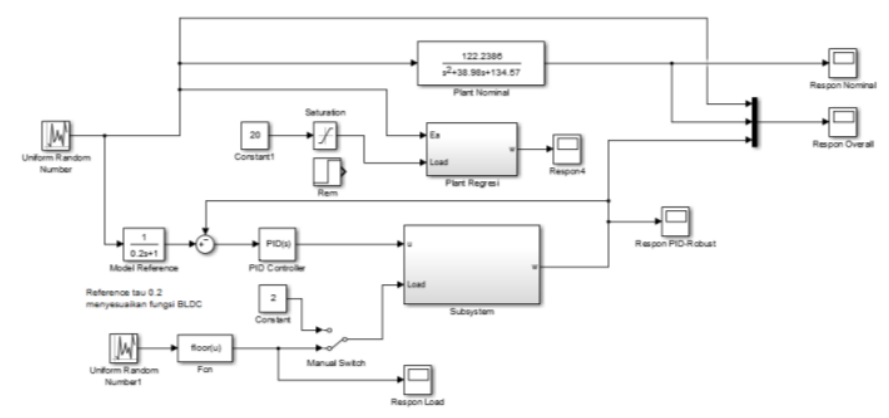

Gambar 5 Diagram Blok Simulasi Kontroler

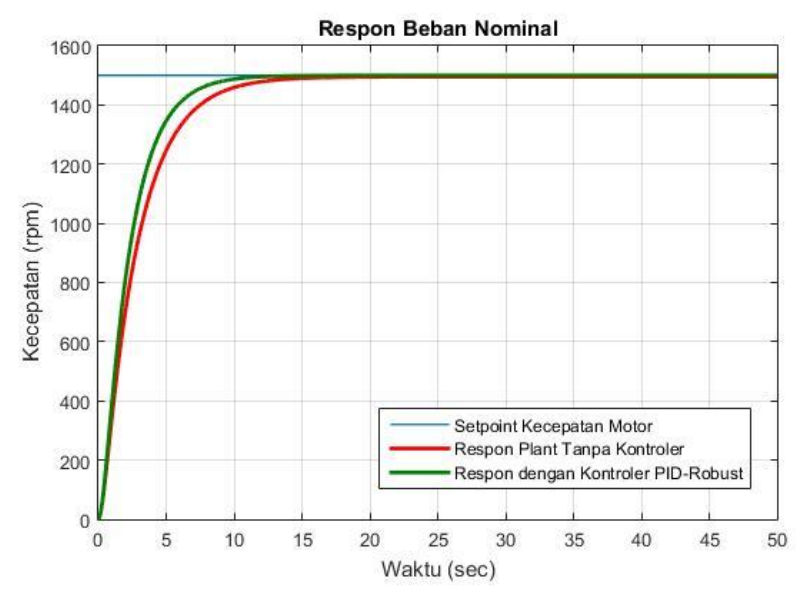

Gambar 6 Hasil Simulasi Respon Model dengan Beban Nominal

Gambar 7, menunjukkan perbandingan antara respon asli dengan respon hasil pemodelan pada keadaan beban nominal, maksimal, dan minimal dengan menggunakan software MATLAB. Terlihat bahwa respon pemodelan plant dengan menggunakan PID-Robust berimpit dengan respon dari model yang diinginkan. Dari Gambar tersebut terlihat bahwa pemodelan plant membutuhkan waktu steady state yang lebih lama dari respon plant yang sebenarnya dikarenakan pemodelan plant mengikuti model yang diinginkan. Waktu untuk mencapai steady state pada respon asli plant sebesar 0.7 detik sedangkan saat diberi kontroler PID-Robust untuk mengikuti steady state pada model yang diinginkan sebesar 6 detik. Kecepatan dari motor dalam bentuk persentase sehingga perlu dikalikan dengan kecepatan maksimal sebesar $1535 \mathrm{rpm}$. 


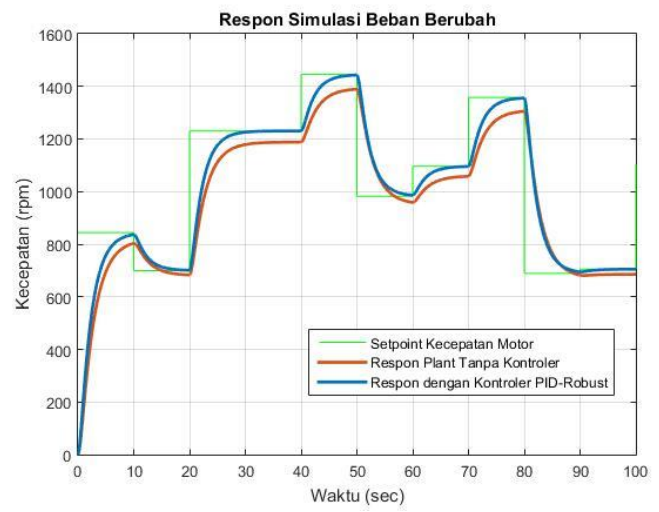

Gambar 7 Hasil Simulasi Respon Model dengan Beban Berubah

Indeks performansi dari respon step dapat dilihat pada Tabel 3 .

Tabel 3.

Indeks Performansi Plant saat Simulasi

\begin{tabular}{lccc}
\hline \hline Indeks Performansi & $\begin{array}{c}\text { PID-Robust } \\
\text { Beban } \\
\text { Minimal }\end{array}$ & $\begin{array}{c}\text { Noban } \\
\text { Nominal }\end{array}$ & $\begin{array}{c}\text { Beban } \\
\text { Maksimal }\end{array}$ \\
\hline$T_{R}$ (detik) & 5,053 & 5,05 & 5,049 \\
$T_{S}$ (detik) & 10,431 & 10,443 & 10,439 \\
RMSE & 0 & 0 & 0 \\
Overshoot $\% M p)$ & 0 & 0 & 0 \\
Error Steady & 0 & 0 & 0 \\
State(Ess) & & & \\
\hline \hline
\end{tabular}

\section{B. Implementasi}

Pada tahapan ini kontroler yang telah dibuat dicoba dijalankan pada plant real motor BLDC P-1. Pengujian ini dilakukan dengan memberikan respon step pada saat plant diberi beban minimal, nominal, dan maksimal.

Pada plant ini sebagian besar bahan dasar yang dipakai untuk dudukan terbuat dari akrilik. Pada plant ini terdapat dua buah PCB yang diantaranya rangkaian board Daikin dan rangkaian isolasi. Setelah itu terdapat 8 buah lilitan kawat yang berfungsi sebagai rem magnetik. Selain itu terdapat 1 buah piringan yang satu terbuat dari alumunium yang berfungsi sebagai beban pada poros.

Motor BLDC yang digunakan ialah motor BLDC yang biasa digunakan pada perangkat Air Conditioner (AC/Pendingin Ruangan). Motor BLDC tersebut merupakan hasil pabrikan dari produsen keperluan pendingin ruangan yang dipergunakan pada plant ini yaitu Daikin D43F. Motor jenis memiliki tegangan nominal 307 VDC. Dilihat dari struktur fisik motor yang cukup lebar, biasanya motor jenis ini memiliki kecepatan putar yang cukup rendah tetapi memiliki torsi yang lebih besar.

Kontruksi rem magnetik adalah baut yang memiliki diameter $1 \mathrm{~cm}$. lalu baut tersebut dililit sebanyak 400 lilitan agar didpatkan medan magnet yang cukup kuat untuk membebani motor BLDC. Pada gambar tersebut juga terlihat ada piringan diantara dua baut yang terbuat dari alumunium setebal $5 \mathrm{~mm}$. diameter dari pringan ini adalah $15 \mathrm{~cm}$. piringan terpasang pada sebuah poros yang terpasang dengan kopel yang terhubung dengan motor. Poros ini juga ikut menyebabkan piringan berputar.

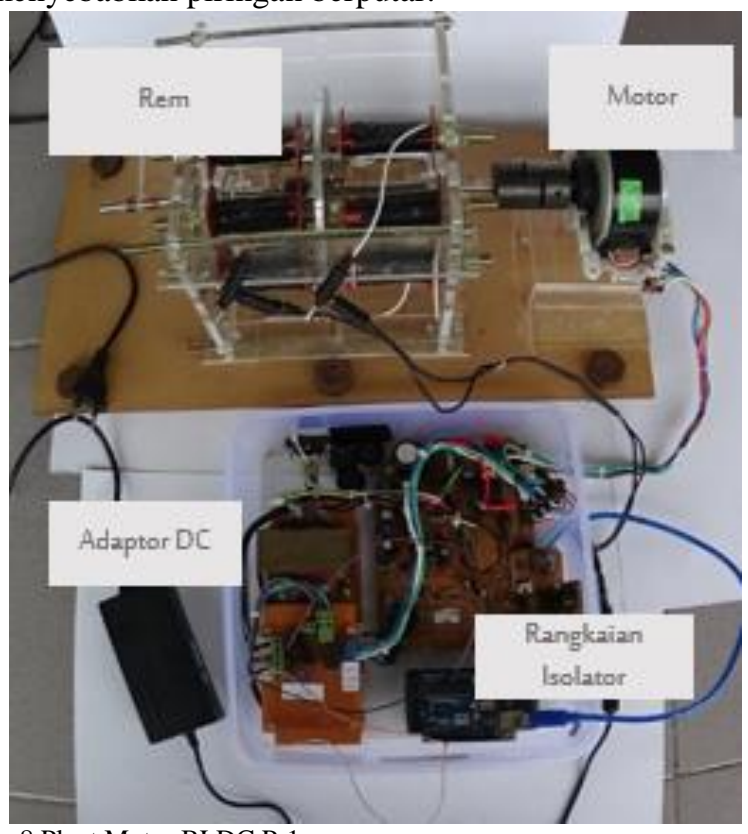

Gambar 8 Plant Motor BLDC P-1

Grafik respon transien output plant dengan PID-Robust pada kondisi beban minimal, nominal, dan maksimal. Dari gambar dapat ditarik kesimpulan bahwa pada saat diberi beban minimal, nominal, maupun maksimal, motor dapat mengikuti respon model referensi yang diinginkan.

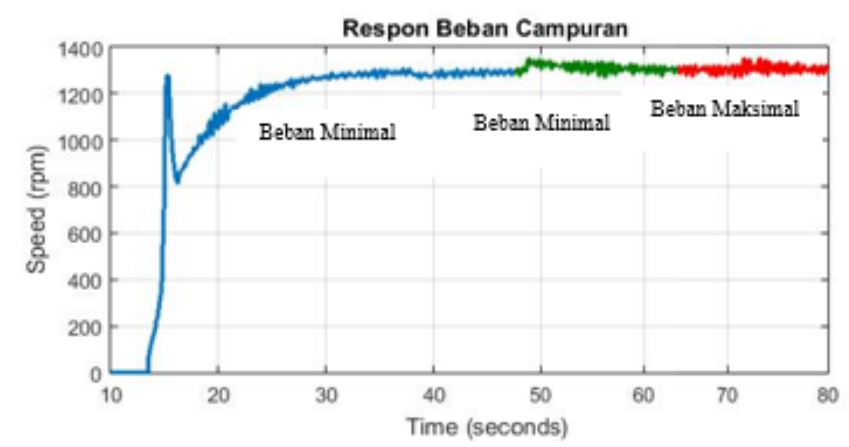

Gambar 9 Step Respon Sistem Beban Berubah

Gambar 10 merupakan hasil respon sistem ketika motor diberi beban minimal, lalu setelah steady beban diubah menjadi beban nominal, dan setelah steady diubah menjadi beban maksimal.

\section{KESIMPULAN}

Dalam pengerjaan penelitian ini dapat disimpulkan bahwa kontroler PID-Robust ini dapat digunakan untuk memperlambat rise time dan juga memperkecil overshoot pada saat dilakukan simulasi. Pada simulasi kontroler beban minimal, nominal, dan maksimal didapatkan respon dengan spesifikasi yang diinginkan. Pengaturan kecepatan menggunakan PID-Robust menghasilkan respon sistem yang dapat mengikuti respon model referensi yang diharapkan. Pada kecepatan dibawah 1000 rpm, sensor kecepatan tidak dapat membaca data dengan baik. 


\section{DAFTAR PUSTAKA}

[1] Guifang CAI, Kun QIAN, dkk “Robust PID Controller in Brushless DC Motor Application", IEEE International Conference on Control and Automation, Guangzhou, CHINA, 2007.

[2] Kazuo Tanaka, Takayuki Ikeda, dan Hua O. Wang, "Robust Stabilization of a Class of Uncertain Nonlinear Systems via Fuzzy Control: Quadratic Stabilizability, Ho Control Theory, and Linear Matrix Inequalities," IEEE Transactions on Fuzzy Systems, vol. 4, no. 1, February 1996.

[3] Katsuhiko Ogata, Modern Control Engineering, 3rd ed. New Jersey: Prentice-Hall, 1997.

[4] S. G. Cao, N. W. Rees, dan G. Feng, "Hळ control of uncertain fuzzy continuous-time systems," Fuzzy Sets and Systems, vol. 115, pp. 171-190, 2000.

Engineering", "Brushless DC Motor http://www.nmbtc.com/brushless-dc$<\mathrm{URL}$ : motors/engineering/brushless_dc_motors_engineering />, 2007.

[6] Putra, Guntur Shadiea, "Perancangan Kontrol Kecepatan Motor Arus Searah Tanpa Sikat Menggunakan Sliding Mode Berbasis PID”, Tugas Akhir Jurusan Teknik Elektro ITS Surabaya, 2015.

[7] "Arduino", <URL: $\overline{\text { http://arduino.cc/> }}$, Mei, 2015. 